Revista Brasileira de

Engenharia Agrícola e Ambiental

v. 15, n.3, p.289-295, 2011

Campina Grande, PB, UAEA/UFCG - http://www.agriambi.com.br

agriambi

Protocolo 073.10 - 19/04/2010 - Aprovado em 09/12/2010

\title{
Viabilidade e micoflora de sementes de amendoim irradiadas com cobalto $\left({ }^{60} \mathrm{Co}\right)^{1}$
}

\author{
Niédja M. C. Alves², Francisco de A. C. Almeida3 ${ }^{3}$ Josivanda P. G omes ${ }^{3}$, \\ Artur S. C. Leal ${ }^{2} \&$ Manasses M. da Silva ${ }^{2}$
}

\begin{abstract}
RESUMO
Estudou-se 0 efeito de diferentes doses da irradiação gama na germinação e percentagem de infecção fúngica em sementes de amendoim cultivar BR1. Inicialmente, as sementes foram avaliadas quanto à micoflora, utilizando-se o método de papel de filtro umedecido, a germinação em substrato de papel germitest e determinação do teor de umidade em estufa, a $105 \pm 2 \circ \mathrm{C}$. Posteriormente, as sementes foram submetidas à irradiação com uma fonte de ${ }^{60} \mathrm{Co}$, tipo gammacell, onde se estudou 0 efeito de 8 doses de irradiação na micoflora e germinação das sementes acondicionadas em embalagem de PET e polietileno trançado durante 60 dias de armazenamento, sem controle de temperatura e umidade relativa do ar. Os fatores estudados (doses em KGy, embalagens e tempo de armazenamento) foram analisados em um delineamento inteiramente casualizado, dispostos em fatorial. Com base nos resultados, observou-se que a irradiação gama afetou negativamente a germinação das sementes de amendoim e que doses acima de 3,0 kG y comprometem a germinação das sementes. A radiação a partir da dose 1,5 kGy eliminou os fungos Aspergillus niger e, Penicillium a partir da dose de 2,5 kG y.
\end{abstract}

Palavras-chave: irradiação gama, germinação, armazenamento

\section{Viability and mycoflora of irradiated seeds of peanut with cobalt $\left({ }^{60} \mathrm{Co}\right)$}

\begin{abstract}
The effect of different doses of the gamma irradiation was studied on germination and percentage of fungal infection in peanut seeds cultivar BR1. Initially the seeds were evaluated for the mycoflora using the method of humidified filter paper, the germination in paper substratum germitest and determination of the moisture content in oven at $105 \pm 2 \stackrel{\circ}{ } \mathrm{C}$. Later on the seeds were submitted to irradiation with a source of ${ }^{60} \mathrm{Co}$, type gammacell, where the effect was studied of 8 doses of irradiation in the mycoflora and germination of the seeds conditioned in PET packing and polyethylene tressed during 60 days of storage, without control of temperature and relative humidity of the air. The studied factors (doses in KG y, packing and time of storage) were analyzed in a completely randomized design arranged in factorial. Scheme-based on the results, it was observed that gamma irradiation affected negatively the germination of the peanut seeds, and that doses above $3.0 \mathrm{kG}$ completely undermine the germination of seeds. The radiation eliminated the fungus Aspergillus niger under the dose of $1.5 \mathrm{kG}$ and the Penicillium under the dose of $2.5 \mathrm{kGy}$.
\end{abstract}

Key words: gamma irradiation, germination, storage

\footnotetext{
${ }^{1}$ Parte da Dissertação de Mestrado do primeiro autor apresentada ao Curso de Pós-Graduação em Engenharia Agrícola

2 Doutorando da UFCG. Fone: (83) 2101-1055. E-mail: niedjamarizze@yahoo.com.br; arturcleal@yahoo.com.br; manasses.ufcg@gmail.com ${ }^{3}$ U AEA/UFCG. Av. Aprígio Veloso, 882, CEP: 58.429-170, Campina Grande, PB. Fone: (83) 2101-1550. E-mail: almeida@deag.ufcg.edu.br; josi@deag.ufcg.edu.br
} 


\section{INTRODUÇÃO}

Os fungos são os principais componentes da microflora presentes nos grãos armazenados e constituem a principal causa das deteriorações e perdas constatadas durante o armazenamento (Tanaka et al., 2001). Estes invadem grãos e sementes em diferentes fases que caracterizam a contaminação por micotoxinas: antes da colheita, durante a colheita, na secagem e no armazenamento ou em todas essas etapas. Os efeitos da invasão fúngica implicam em significativa perda de qualidade do produto como, por exemplo, de germinação, descoloração, odor, aquecimento da massa, crescimento fúngico e produção de micotoxinas (Hermanns et al., 2006).

A técnica de irradiação ionizante é um processo físico que surge como prática promissora para manter por mais tempo os grãos e as sementes ao longo da armazenagem, conferindo-lhe segurança, em virtude do controle dos micro-organismos, em especial os insetos e fungos (Toledo et al., 2007; Braghini et al., 2009).

Algumas pesquisas descritas na literatura mundial destacam a eficiência da irradiação gama, em diferentes doses, na destruição de espécies fúngicas de Aspergillus e Penicillium em diferentes alimentos (Zanão et al., 2009). O tratamento das sementes com irradiação gama elimina os micro-organismos que contribuem para sua deterioração depois da colheita; no entanto, carece de mais estudos para ser utilizada nos programas de melhoramento e na comercialização.

A irradiação em alimentos com o objetivo de reduzir a microbiota natural ou patogênica e aumentar a vida de prateleira dos produtos, é uma das tecnologias que vêm crescendo em todo o mundo mas ainda pouco difundida no Brasil. Atualmente, especiarias, grãos, carnes, frutas e vegetais, são tratados por este processo com diferentes propósitos: (1) retardamento do amadurecimento de frutos; (2) desinfecção, com eliminação de insetos adultos, larvas e ovos e (3) prevenção do brotamento de vegetais. Devido ao aumento do comércio internacional de alimentos e das crescentes exigências dos regulamentos dos países consumidores, são fundamentais o desenvolvimento e o domínio de pesquisas que visem avaliar a irradiação como processo capaz de melhorar a qualidade e aumentar a vida de prateleira desses alimentos.

No Brasil, a legislação que trata do emprego da irradiação em alimentos é a Resolução RDC n ${ }^{\circ} 21$, de 21 de janeiro de 2001, da Agência Nacional de Vigilância Sanitária do Ministério da Saúde (Brasil, 2001). As doses a serem aplicadas devem ser compatíveis com os efeitos desejados, não tendo a legislação fixado valores mínimos ou máximos.

Os três tipos de fontes de radiação disponíveis para o processamento de alimentos, são: aceleradores de elétrons e máquinas de raios $\mathrm{X}$ e fontes de radioisótopos, como o ${ }^{60} \mathrm{Co} \mathrm{e}$ o ${ }^{137}$ Cs (Lima et al., 2003).

Ante os fatos relatados objetivou-se, com este trabalho, estudar o efeito das diferentes doses da irradiação gama $\left({ }^{60} \mathrm{Co}\right)$, na percentagem de germinação e infecção fúngica em amendoim cultivar BR1.

\section{MATERIAL E MÉTODOS}

O experimento foi realizado no Laboratório de Armazenamento e Processamento de Produtos Agrícolas (LAPPA) da Unidade Acadêmica de Engenharia Agrícola (UAEA) do Centro de Tecnologia e Recursos Naturais (CTRN), da Universidade Federal de Campina Grande (UFCG). A irradiação das sementes de amendoim, cultivar BR1, foi realizada no Departamento de Energia Nuclear da UFPE.

\section{Obtenção da matéria-prima}

Utilizaram-se sementes de amendoim, cultivar BR1, produzidas em campos experimentais de sementes da Embrapa Algodão, Patos, PB, da safra do primeiro semestre de 2008.

Para início dos trabalhos as sementes foram avaliadas quanto à germinação e teor de umidade (Brasil, 2009) e micoflora (Neergaard, 1979).

\section{Determinação da micoflora}

Empregou-se o método do papel de filtro umedecido (Neergaard, 1979), em que foram utilizadas 40 sementes de cada lote as quais, em número de 10 por repetição, foram distribuídas igualmente e espaçadas sobre uma camada constituída de três folhas sobrepostas de papel de filtro umedecido com água destilada esterilizada (ADE) e contido em placa de Petri $(\varnothing=$ $9,5 \mathrm{~cm}$ ); após a distribuição das sementes, as placas de Petri foram mantidas em ambiente de laboratório (não controlado); no oitavo dia de incubação as sementes foram observadas ao microscópio estereoscópico para a identificação dos fungos, considerando-se as características de suas colônias e avaliação de incidência.

\section{Teor de umidade}

Utilizou-se o método da estufa a $105 \pm 2{ }^{\circ} \mathrm{C}$, com 3 subamostras de $20 \mathrm{~g}$ acondicionadas em recipientes metálicos, previamente secados, pesados e colocados em estufa, durante 24 h; após este período, os recipientes foram retirados da estufa e postos em um dessecador, pelo tempo de 45 min (Brasil, 2009); em seguida, as sementes foram novamente pesadas obtendose a percentagem de peso, expressa em base úmida.

\section{Teste de germinação}

Realizou-se o teste de germinação em laboratório utilizandose quatro repetições de 50 sementes semeadas em folhas de papel 'germitest', sendo duas na base e uma folha em cobertura, umedecidas em água destilada, na proporção de três vezes o peso do papel seco. Rolos foram confeccionados e acomodados em recipiente plástico para evitar perda de umidade e, posteriormente, colocados no germinador (BOD, Modelo101/3) regulado a temperatura de $25 \pm 1{ }^{\circ} \mathrm{C}$, no qual a umidade relativa foi mantida em torno de $95 \pm 2 \%$, motivo por que cubas com água foram colocadas na parte inferior do germinador. Realizouse a avaliação nos 5 e $10^{\circ}$ dias após a semeadura, computandose o percentual de plântulas normais (Brasil, 2009).

Tratamento das sementes com irradiação de cobalto- $60\left({ }^{60} \mathrm{Co}\right)$

O processo de irradiação das sementes de amendoim, cultivar BR1, para controle da micoflora, foi feito em um irradiador que 
emite raios a partir de ${ }^{60} \mathrm{Co}$. As amostras de $200 \mathrm{~g}$ de sementes com teor de umidade de $8,01 \%$ correspondentes a cada lote, foram acondicionadas em embalagem do tipo PET, antes de serem colocadas no irradiador, para evitar contaminação após a irradiação por exposição ao ambiente. As doses de radiação gama utilizadas foram: $0 ; 0,50 ; 1,00 ; 1,50 ; 2,00 ; 2,50 ; 3,00$ e 4,00 $\mathrm{kGy}$; depois de irradiadas, as sementes foram transportadas em suas embalagens intactas para o LAPPA, onde foram submetidas à determinação da micoflora, teor de umidade e testes de germinação; em seguida, quarenta amostras, acondicionadas nas embalagens PET, foram transferidas para embalagens de polietileno trançado, formando-se dois lotes com $16 \mathrm{~kg}$ cada lote.

Os resultados foram analisados no delineamento inteiramente casualizado (DIC), dispostos em esquema fatorial $(8 \times 2 \times 3)$, representado por: doses de ${ }^{60} \mathrm{Co}$, embalagem de PET e polietileno trançado e tempo de armazenamento, respectivamente. As médias foram comparadas pelo teste de Tukey a 1 e $5 \%$ de probabilidade. O programa estatístico utilizado foi o Assistat, versão 7.4. beta (Silva \& Azevedo, 2006).

\section{RESULTADOS E DISCUSSÃO}

Os resumos das análises de variância e o coeficiente de variação correspondente ao teor de umidade das sementes de amendoim armazenadas em ambiente não controlado do LAPPA, pelo tempo de 60 dias, em embalagens de PET e polietileno trançado e irradiadas $\mathrm{com}{ }^{60} \mathrm{Co}$, encontram-se na Tabela 1, em que se observa efeito significativo para todas as variáveis e suas interações.

Tabela 1. Análise de variância dos valores médios do teor de umidade (\%) das sementes de amendoim irradiadas com ${ }^{60} \mathrm{Co}$ em diferentes doses e armazenadas durante 60 dias, em embalagem de PET e polietileno trançado

\begin{tabular}{lcrrr}
\hline \multicolumn{1}{c}{ FV } & GL & \multicolumn{1}{c}{ SQ } & \multicolumn{1}{c}{ QM } & \multicolumn{1}{c}{$\mathbf{F}$} \\
Dose (D) & 7 & 1,98 & 0,28 & $14,23^{* *}$ \\
Embalagem (E) & 1 & 2,16 & 2,16 & $108,50^{* *}$ \\
Tempo (T) & 2 & 27,64 & 13,82 & $694,47^{* *}$ \\
ExD & 7 & 1,04 & 0,14 & $7,50^{* *}$ \\
ExT & 14 & 1,92 & 0,13 & $6,91^{* *}$ \\
D x & 2 & 4,43 & 2,21 & $111,47^{* *}$ \\
ExD x T & 14 & 2,10 & 0,15 & $7,55^{* *}$ \\
\hline Tratamento & 47 & 41,31 & 0,87 & $44,15^{* *}$ \\
\hline Resíduo & 48 & 0,95 & - & 0,01 \\
\hline Total & 95 & 42,26 & 42,26 & - \\
\hline
\end{tabular}

** Significativo ao nível de $1 \%$ de probabilidade

Em análise aos dados da Tabela 2, tem-se que a umidade das sementes de amendoim tende ao equilíbrio com a umidade da atmosfera, de forma diferente para os tratamentos embalagem e tempo e que a umidade aumentou com o tempo de armazenamento.

Com relação às embalagens verifica-se, estatisticamente, que a umidade das sementes armazenadas durante os 60 dias em embalagem de PET foi maior frente à de polietileno trançado.
Tabela 2. Valores médios do teor de umidade (\%) das sementes de amendoim irradiadas com ${ }^{60} \mathrm{Co}$ em diferentes doses e armazenadas 60 dias em embalagem de PET e polietileno trançado

\begin{tabular}{cccccc}
\hline \multicolumn{2}{c}{ Dose (KGy) } & Embalagem & \multicolumn{2}{c}{ Tempo (dias) } \\
0,00 & $8,83 \mathrm{a}$ & & & 08 & $8,01 \mathrm{c}$ \\
0,50 & $8,51 \mathrm{~b}$ & & & & \\
1,00 & $8,50 \mathrm{~b}$ & PET & $8,78 \mathrm{a}$ & 30 & $8,57 \mathrm{~b}$ \\
1,50 & $8,83 \mathrm{a}$ & & & & \\
2,00 & $8,77 \mathrm{a}$ & & & & \\
\hline 2,50 & $8,47 \mathrm{~b}$ & & & & \\
3,00 & $8,56 \mathrm{~b}$ & PeT & $8,48 \mathrm{~b}$ & 60 & $9,32 \mathrm{a}$ \\
4,00 & $8,57 \mathrm{~b}$ & & & & \\
\hline \multicolumn{7}{l}{ DMS } & 0,18 & DMS & 0,05 & DMS & 0,08 \\
\hline PET - Politereftalato de etileno; PeT - Polietileno trançado & &
\end{tabular}

Para o fator dose houve igualdade estatística para 0,$0 ; 1,50$ e 2,00 kGy (8,81\%) e 0,50; 1,00; 2,50; 3,00 e 4,00 kGy (8,52\%). Em geral, para os fatores dose e embalagens a influência da umidade foi pequena quando comparada com o tempo devendo-se, provavelmente, essas variações, à umidade relativa do ar e temperatura durante o período do armazenamento, atribuições que concordam com as afirmações de Diniz et al. (2001) em estudo de micoflora com amendoim.

Na Tabela 3 se encontram os quadrados médios das análises de variância e o coeficiente de variação correspondente à percentagem de fungos presentes nas sementes de amendoim irradiadas com ${ }^{60} \mathrm{Co}$ e armazenadas em ambiente não controlado do LAPPA, pelo tempo de 60 dias, em embalagens de PET e polietileno trançado, em que se observa efeito altamente significativo para todas as variáveis e suas interações.

Tabela 3. Análise de variância da incidência de fungos nas sementes de amendoim variedade BR1 irradiadas com ${ }^{60} \mathrm{Co}$ e armazenadas em ambiente não controlado durante 60 dias em embalagem de PET e polietileno trançado

\begin{tabular}{|c|c|c|c|c|c|}
\hline \multirow[b]{2}{*}{ F.V } & \multirow[b]{2}{*}{ G.L } & \multicolumn{4}{|c|}{ Fungos } \\
\hline & & $\begin{array}{c}\text { A. flavus } \\
\text { QM }\end{array}$ & $\begin{array}{c}\text { A. niger } \\
\text { QM }\end{array}$ & $\begin{array}{c}\text { Rhizopus } \\
\text { QM }\end{array}$ & $\begin{array}{c}\text { Penicillium } \\
\text { QM }\end{array}$ \\
\hline $\begin{array}{l}\text { D } \\
\text { E } \\
T \\
D \times E \\
D x T \\
\text { DxExT }\end{array}$ & $\begin{array}{r}7 \\
1 \\
2 \\
7 \\
14 \\
14\end{array}$ & $\begin{array}{r}20305,65^{* *} \\
8802,08 * * \\
12084,89 * * \\
731,84 * * \\
688,46^{* *} \\
824,93\end{array}$ & $\begin{array}{c}7365,40 * * \\
275,52 * * \\
520,31 * * \\
151,71 * * \\
159,59 * * \\
90,55\end{array}$ & $\begin{array}{r}2788,98^{* *} \\
1633,33^{* *} \\
314,06^{* *} \\
2358,33^{* *} \\
1241,44^{* *} \\
901,41\end{array}$ & $\begin{array}{r}3564,80^{* *} \\
638,02^{* *} \\
5753,64 * * \\
190,40 * * \\
1030,43^{* *} \\
260,04\end{array}$ \\
\hline $\mathrm{R}$ & 144 & 25,34 & 6,07 & 14,58 & 8,15 \\
\hline C.V (\%) & & & 22,22 & 17,21 & 26,24 \\
\hline
\end{tabular}

Em observação aos resultados contidos na Tabela 4, verificou-se que os fungos que se desenvolveram sobre as sementes de amendoim irradiadas pertencem aos gêneros Aspergillus flavus, Aspergillus niger, Rhizopus e Penicillium e que a porcentagem de incidência do A. flavus nas sementes diminui com o aumento da dose de irradiação.

Para a incidência de A. flavus em ambas as embalagens, observa-se redução à medida em que se eleva a dose da irradiação, com controle total (100\%) para a embalagem de PET na dose de 4,0 kGy e de 78,33\% para o armazenamento em 
Tabela 4. Valores médios da incidência (\%) de fungos para a interação $D \times E$ em sementes de amendoim irradiadas com ${ }^{60} \mathrm{Co}$ e armazenadas em ambiente não controlado, durante 60 dias

\begin{tabular}{|c|c|c|c|c|c|c|c|c|}
\hline \multirow{3}{*}{$\begin{array}{l}\text { Doses } \\
\text { (KGy) }\end{array}$} & \multicolumn{8}{|c|}{ Embalagem } \\
\hline & \multicolumn{2}{|c|}{ A. flavus } & \multicolumn{2}{|c|}{ A. niger } & \multicolumn{2}{|c|}{ Rhizopus } & \multicolumn{2}{|c|}{ Penicillium } \\
\hline & PET & PeT & PET & PeT & PET & PeT & PET & PeT \\
\hline 0,0 & $85,83 a A$ & $87,50 a A$ & $33,33 a \mathrm{a}$ & $46,67 \mathrm{aA}$ & $45,83 a A$ & $35,00 \mathrm{aB}$ & $30,83 a \mathrm{~B}$ & $46,67 \mathrm{aA}$ \\
\hline 0,5 & $65,00 \mathrm{bB}$ & $82,50 \mathrm{aA}$ & $34,17 \mathrm{aB}$ & $40,83 \mathrm{bA}$ & $38,33 \mathrm{bA}$ & $6,67 \mathrm{deB}$ & $10,00 \mathrm{bA}$ & $10,83 \mathrm{cA}$ \\
\hline 1,0 & $30,83 \mathrm{CA}$ & $31,67 \mathrm{CA}$ & $11,67 \mathrm{bA}$ & $10,83 \mathrm{cA}$ & $45,00 \mathrm{aA}$ & $18,33 \mathrm{cB}$ & $10,00 \mathrm{bB}$ & $15,83 \mathrm{bA}$ \\
\hline 1,5 & $22,50 \mathrm{~dB}$ & $53,33 b A$ & $0,00 c A$ & $0,00 \mathrm{dA}$ & $10,00 \mathrm{eB}$ & $21,67 \mathrm{bcA}$ & $10,00 \mathrm{bA}$ & $8,33 \mathrm{cA}$ \\
\hline 2,0 & $22,50 \mathrm{~dB}$ & $50,00 \mathrm{bA}$ & $0,00 \mathrm{cA}$ & $0,00 \mathrm{dA}$ & $20,00 \mathrm{~dB}$ & $33,33 \mathrm{aA}$ & $7,50 b c B$ & $10,00 \mathrm{cA}$ \\
\hline 2,5 & $16,67 \mathrm{~dB}$ & $25,83 \mathrm{cA}$ & $0,00 \mathrm{cA}$ & $0,00 \mathrm{dA}$ & $13,33 \mathrm{eB}$ & $25,00 \mathrm{bA}$ & $4,17 c B$ & $10,00 \mathrm{CA}$ \\
\hline 3,0 & $3,33 \mathrm{eB}$ & $15,00 \mathrm{dA}$ & $0,00 \mathrm{cA}$ & $0,00 \mathrm{dA}$ & $28,33 \mathrm{cA}$ & $3,33 \mathrm{eB}$ & $0,00 \mathrm{dA}$ & $0,00 \mathrm{dA}$ \\
\hline 4,0 & $0,00 \mathrm{eB}$ & $9,17 \mathrm{dA}$ & $0,00 \mathrm{cA}$ & $0,00 \mathrm{dA}$ & $0,00 f B$ & $10,83 \mathrm{dA}$ & $0,00 \mathrm{dA}$ & $0,00 \mathrm{dA}$ \\
\hline $\mathrm{DMS}(\mathrm{C})$ & \multicolumn{2}{|c|}{6,31} & \multicolumn{2}{|c|}{3,09} & \multicolumn{2}{|c|}{4,78} & \multicolumn{2}{|c|}{3,58} \\
\hline $\mathrm{DMS}(\mathrm{L})$ & \multicolumn{2}{|c|}{4,06} & \multicolumn{2}{|c|}{1,98} & \multicolumn{2}{|c|}{3,08} & \multicolumn{2}{|c|}{2,30} \\
\hline
\end{tabular}

Médias seguida da mesma letra minúscula na coluna e maiúscula na linha não diferem estatisticamente pelo teste de Tukey a $5 \%$ de probabilidade; Umidade Inicial = 8,01\%; micoflora inicial = 55\% de A. flavus; 36,67 de A. niger e 36,67\% de Rhizopus. PeT -Polietileno trançado; PET - Politereftalato de etileno

embalagem de polietileno trançado. É de registro para esta embalagem, à exceção das doses de 1,0 e 2,5 kGy, que a redução se deu gradualmente com o aumento das doses, como ocorreu com todas as doses na embalagem de PET.

Examinando o efeito das embalagens para o A. flavus utilizadas na conservação das sementes de amendoim ao longo do armazenamento, observa-se que a embalagem de PET superou, em termos de valores absolutos, a embalagem de polietileno trançado, em todas as doses.

A contaminação por $A$. niger diminuiu em ambas as embalagens, até a dose de 1,0 kGy, a partir da qual teve controle total $(0,0 \%)$, com igualdade estatística entre as embalagens na dose de $1 \mathrm{kGy}$ e dentro da embalagem PET, na dose 0,0 e 0,5 $\mathrm{kGy}$, com superioridade para a embalagem de PET.

O Rhizopus comportou-se de forma diferente aos fungos anteriormente analisados (A. flavus e A. niger), quanto à uniformidade de controle, em decorrência das doses, vez que na embalagem de PET para as doses de 1,00 e 3,00 kGy houve aumento da incidência de fungos com relação às doses anteriores. Entre as embalagens há comportamento uniforme para as doses de 0,0 a $1,0 \mathrm{kGy}$, em que a embalagem de polietileno trançado foi melhor no controle deste fungo que a de PET, ocorrendo o inverso para as doses de 1,5 a 2,5 kGy. Na dose de 4 kGy o controle do Rhizopus foi absoluto com a embalagem de PET; comportamento similar apresentou o Penicillium, em relação aos fungos A. flavus e A. niger, isto é, a contaminação diminui com o aumento das doses em ambas as embalagens com exceção da dose de 1,0 kGy na embalagem de polietileno trançado, com controle total a partir da dose de 3,0 kGy.

Entre as embalagens para as doses de 2,0 e 2,5 kGy ocorreu menor incidência de Penicillium na embalagem de PET, não havendo diferença estatística entre essas embalagens, para as doses de 0,5 e $1,5 \mathrm{kGy}$.

A diferença de comportamento dentro e entre as embalagens se deve, provavelmente, à competição entre os fungos por substrato e espaço, em que o A. flavus e o A. niger são mais agressivos que o Rhizopus e o Penicillium. Em parte, esses resultados concordam com as observações de Rossetto et al. (2003) que trabalharam com distribuição de fungos em variedade de amendoim armazenado e constataram que a influência mútua entre os fungos pode ocorrer de modo antagônico.
Santos et al. (2010) estudaram o efeito da irradiação gama $\left({ }^{60} \mathrm{Co}\right)$ no desenvolvimento de fungos em sementes de amendoim armazenadas e concluiu que a infestação diminuiu com o aumento das doses de irradiação e a dose 2,0 kGy controlou, em $100 \%$, os fungos A. flavus e A. niger.

A radiação gama tem sido utilizada por alguns pesquisadores no controle de micro-organismos, em que a influência da dose de irradiação para eliminar a microbiótica fúngica foi estudada por Prado et al. (2003) em amendoim e Fanaro et al. (2004) em sementes de girassol, constatando que a radiação mostrou eficiência na redução da incidência de micro-organismos.

Na Figura 1 constam os resultados da micoflora revelados pela interação Dose x Tempo das sementes de amendoim irradiadas $\operatorname{com}^{60} \mathrm{Co}$, acondicionadas em embalagem de PET e polietileno trançado.

Observando-se a representação gráfica da Figura 1 (A), para $\mathrm{o}$ A. flavus, dentro de cada dose, tem-se maior incidência deste fungo à medida em que o tempo de armazenamento avança, exceto para a dose de $1,5 \mathrm{kGy}$, no tempo de 30 dias. No início do armazenamento o percentual de contaminação de $65 \%$ para as sementes irradiadas com $0,5 \mathrm{kGy}$ elevou-se para $78,75 \%$ depois do período de armazenamento e para a dose de 4,0 kGy, que, inicialmente, foi de 0,0 para $8,75 \%$ ao final do armazenamento. Este comportamento indica que o efeito da irradiação diminui com o tempo de armazenamento sugerindo maiores estudos com relação ao tempo, para confirmação da microbiota fúngica. Observa-se, também, que antes da armazenagem as sementes de amendoim apresentaram incidência de $70 \%$ de A. flavus e, depois do período de armazenamento (60 dias) a testemunha estava totalmente contaminada (100\%).

Prado et al. (2006), analisando o efeito da irradiação gama $\left({ }^{60} \mathrm{Co}\right)$ na frequência fúngica de amendoim in natura em função do tempo de prateleira, observaram que a irradiação gama $\left({ }^{60} \mathrm{Co}\right)$ na dose de $5 \mathrm{kGy}$ é capaz de reduzir a porcentagem fúngica de amendoim em grão, após 20,60 e 180 dias, a temperatura ambiente.

Para o A. niger, nota-se que da dose 0,0 para 1,0 kGy ocorreu um aumento no percentual de incidência deste fungo com o tempo de armazenamento; já a partir da dose de 1,5 kGy houve controle total do mesmo. Com relação ao fungo Rhizopus, verifica-se diminuição nas sementes não irradiadas e ausência 


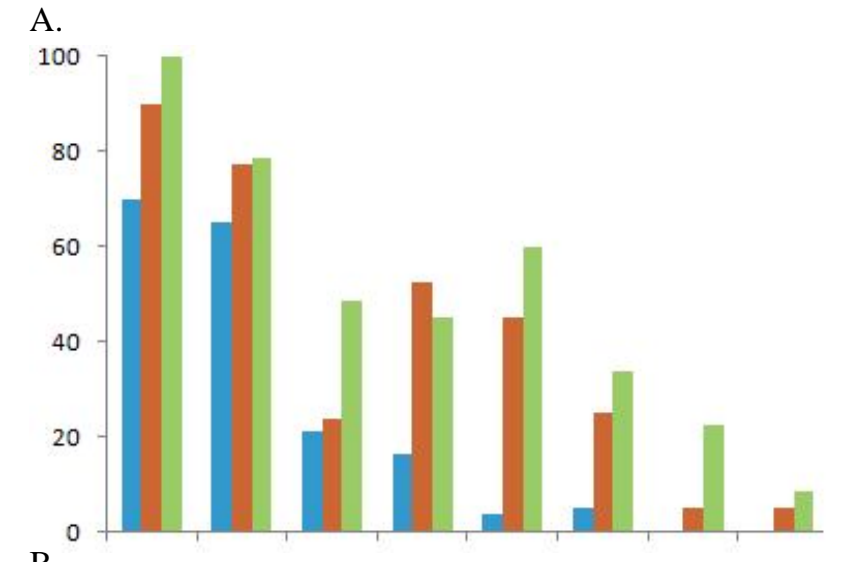

B.
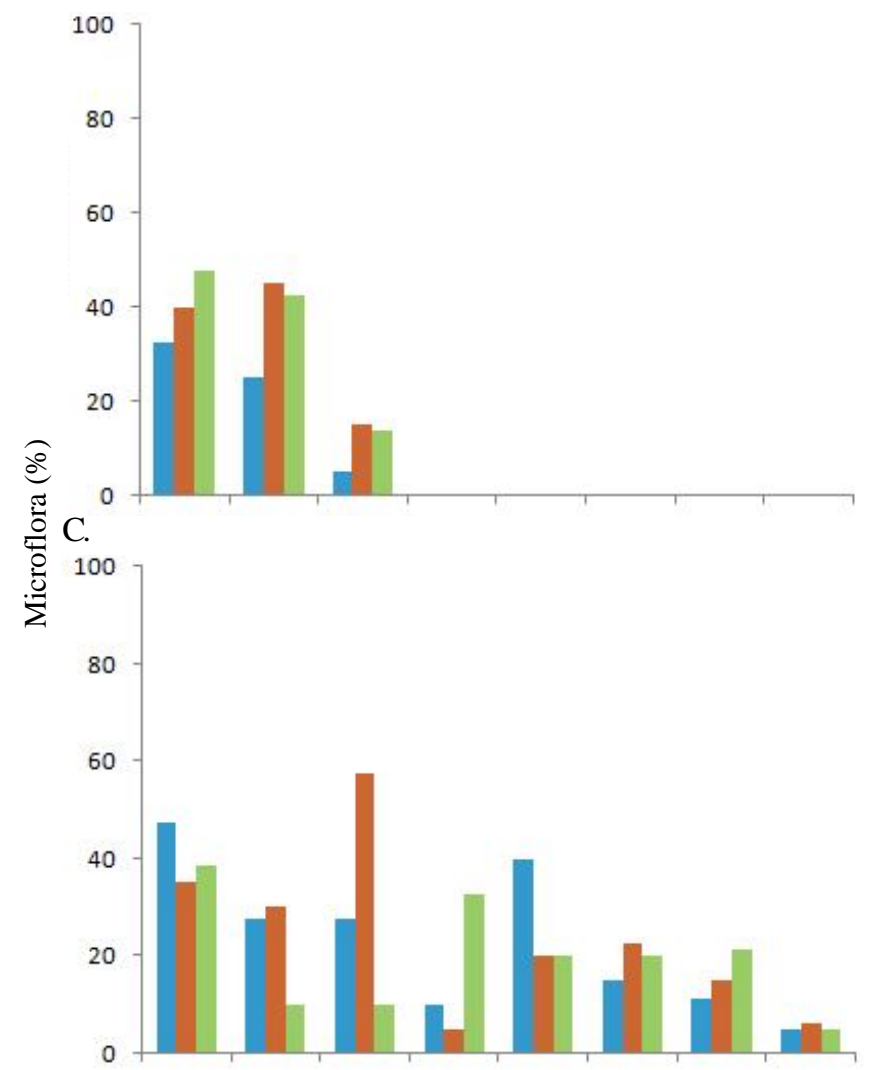

D.

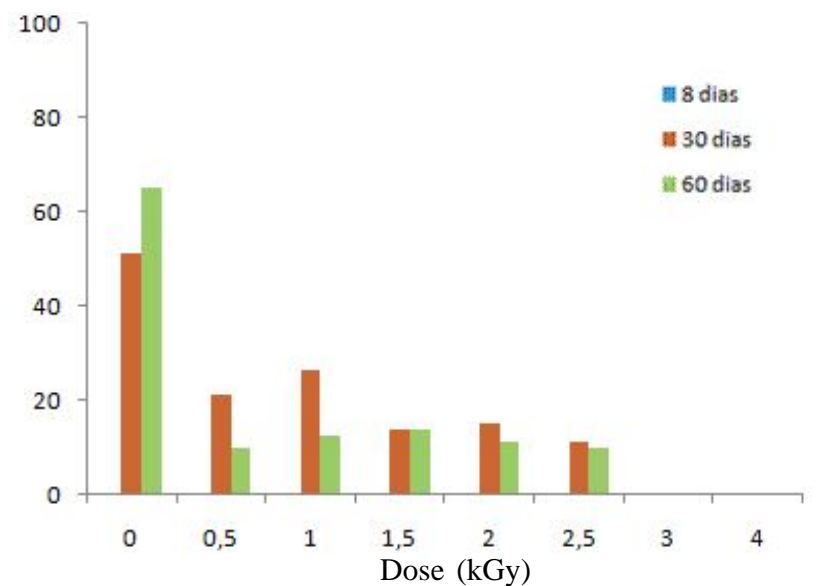

Figura 1. Representação gráfica da porcentagem de $A$. flavus (A), A. niger (B), Rhizopus (C) e Penicillium (D) para as diferentes doses de irradiação gama e tempo de armazenamento no início do armazenamento e, para o Penicillium, controle total deste fungo nas doses de 3,0 e 4,0 kGy para as embalagens de PET e polietileno trançado.

Os resumos das análises de variância correspondente à germinação das sementes de amendoim armazenadas em ambiente não controlado do LAPPA pelo tempo de 60 dias, em embalagens de PET e polietileno trançado e irradiadas com ${ }^{60} \mathrm{Co}$, se encontram na Tabela 5 , em que se observa efeito altamente significativo para todas as variáveis e suas interações.

Tabela 5. Análise de variância da germinação de sementes de amendoim variedade BR1 irradiadas com ${ }^{60} \mathrm{Co}$ e armazenadas em ambiente não controlado, durante 60 dias

\begin{tabular}{lrc}
\hline \multicolumn{1}{c}{ F.V } & G.L & Q.M \\
Dose (D) & 7 & $6974,25^{* *}$ \\
Embalagem (E) & 1 & $1716,02^{* *}$ \\
Tempo (T) & 2 & $5416,28^{* *}$ \\
D x E & 7 & $186,59^{* *}$ \\
D X T & 14 & $167,88^{* *}$ \\
Ex D X & 14 & 136,23 \\
\hline Resíduo & 144 & 0,42 \\
\hline ** Significativo a 1\% de probabilidade &
\end{tabular}

Os resultados apresentados na Tabela 6 e na Figura 2, evidenciam os efeitos das doses de irradiação gama sobre a germinação das sementes de amendoim indicando o efeito prejudicial no sentido de que a germinação reduz com o aumento da aplicação da dose de irradiação.

De acordo com os resultados tem-se, para as sementes não irradiadas, germinação de 61,67 e $60,58 \%$, respectivamente, para o armazenamento em PET e polietileno trançado, e que a perda da germinação aumenta com o aumento da dose de irradiação, à exceção da dose de $0,5 \mathrm{kGy}$, para a embalagem de PET. Observa-se, também, que tanto a embalagem de PET quanto a embalagem de polietileno trançado se comportaram similarmente com o aumento das doses de irradiação, isto é, a germinação diminuiu sempre que estas foram aumentadas. Constata-se, também, forte redução da germinação a partir da dose de 2,5 kGy, tanto em embalagem de PET como em

Tabela 6. Valores médios da germinação (\%) para a interação $D$ x E em sementes de amendoim irradiadas com ${ }^{60} \mathrm{Co}$ e armazenadas em ambiente não controlado, durante 60 dias

\begin{tabular}{ccc}
\hline \multirow{2}{*}{ Doses (kGy) } & \multicolumn{2}{c}{ Embalagens } \\
\cline { 2 - 3 } & PET & Polietileno trançado \\
0 & $61,67 \mathrm{bA}$ & $60,58 \mathrm{aB}$ \\
0,50 & $66,33 \mathrm{aA}$ & $54,41 \mathrm{bB}$ \\
1,00 & $49,25 \mathrm{cB}$ & $52,25 \mathrm{cA}$ \\
1,50 & $47,91 \mathrm{dA}$ & $33,50 \mathrm{~dB}$ \\
2,00 & $35,83 \mathrm{eA}$ & $31,83 \mathrm{eB}$ \\
2,50 & $32,67 \mathrm{fA}$ & $26,25 \mathrm{fB}$ \\
3,00 & $26,33 \mathrm{gA}$ & $18,83 \mathrm{gB}$ \\
4,00 & $18,08 \mathrm{ha}$ & $12,58 \mathrm{hB}$ \\
\hline CV $(\%)$ & \multicolumn{3}{c}{1,66} \\
\hline
\end{tabular}

Médias seguidas da mesma letra minúscula na coluna (DMS $=0,82$ ) e maiúscula na linha (DMS $=0,52)$ não diferem estatisticamente pelo Teste de Tukey de $5 \%$ de probabilidade; Germinação inicial $=76 \%$; Umidade inicial $=8,01 \% ;$ PET - Politereftalato de etileno 


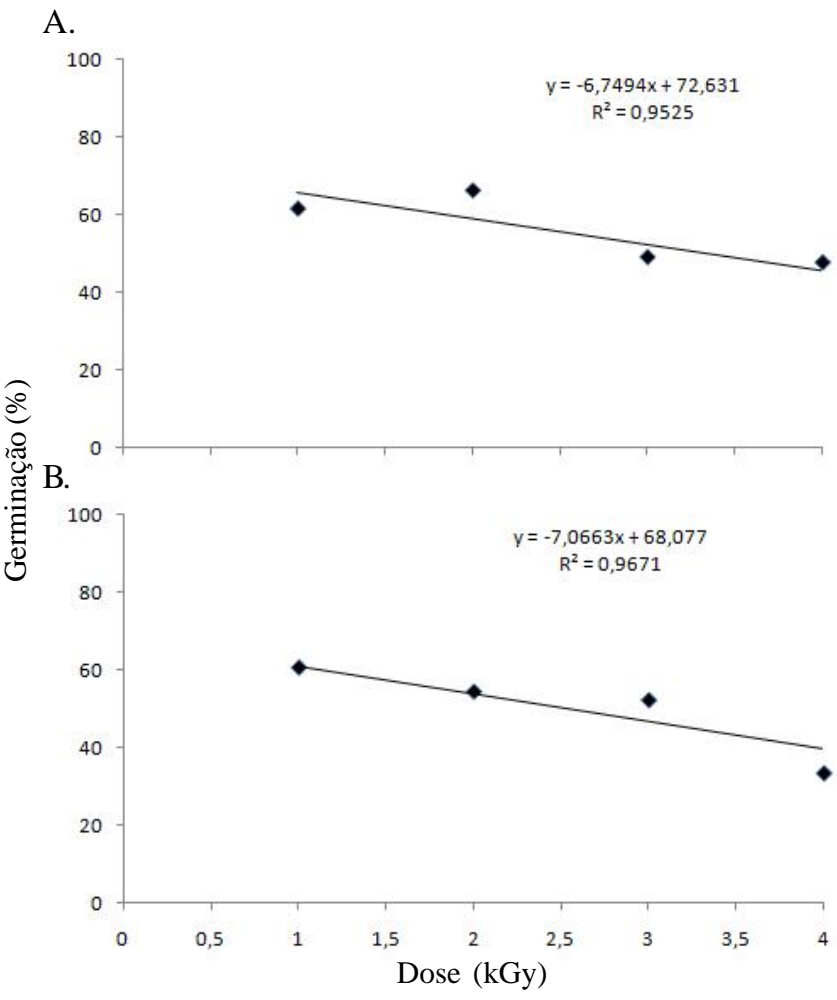

Figura 2. Porcentagem de germinação das sementes irradiadas e armazenadas em embalagem de PET (A) e polietileno trançado (B), por 60 dias

embalagem de polietileno trançado com diminuição da germinação em 47,02, 57,30 e 70,68\% e de 56,67, 68,92, 79,23\% para as doses de 2,5, 3,0 e 4,0 kGy nas embalagens de PET e polietileno trançado, respectivamente.

O estudo das equações polinomiais revelou efeito significativo e $\mathrm{R}^{2}$ acima de $98 \%$ para equações de primeiro grau, indicando que elas podem ser utilizadas para representar o comportamento da germinação de sementes irradiadas neste trabalho (Figura 2). Referidas equações representam estatisticamente o comportamento das sementes irradiadas e acondicionadas em embalagem de PET e polietileno trançado e são importantes por estimarem os pontos intermediários entre os valores obtidos experimentalmente com os relativos às doses de 0,0 a 4,0 kGy. Estudo sobre o tema revela que baixas doses de radiação apresentam a capacidade de estimular os biossistemas, invertendo o efeito com o aumento da dose (Lukey, 1980), o que pode explicar o resultado do aumento da germinação ocorrido na embalagem de PET para a irradiação de 0,5 kGy; entretanto, esta teoria, denominada Hormese, ainda não é muito compreendida nem justificada.

Fanaro et al. (2004), realizando teste em sementes de girassol irradiadas, concluíram que as amostras irradiadas com a dose de $0,5 \mathrm{kGy}$ apresentaram o percentual de germinação muito similar com as sementes não irradiadas (testemunha), diferindo das outras, que tiveram o percentual inferior ao da testemunha.

Santos et al. (2010), em estudo de viabilidade submeteram sementes de amendoim, variedade Havana, a várias doses de irradiação e, em seguida, analisando sua micoflora, tendo concluído que o tratamento com radiação gama afetou negativamente o vigor e a germinação das sementes de amendoim; as doses de 0,5, e 1,5 kGy resultaram em perda de germinação e vigor acima de 50\%; a dose de $3 \mathrm{kGy}$ inviabiliza a utilização das sementes para o plantio e doses acima de $12 \mathrm{kGy}$ comprometem totalmente o vigor e a germinação das sementes.

Verifica-se, no presente trabalho, uma forte redução da germinação das sementes irradiadas a partir da dose de 3,0 kGy em que a percentagem da germinação caiu em $35,34 \%$ em relação à testemunha $(0,0 \mathrm{kGy})$ para a embalagem de PET e a partir da dose de 2,5 kGy, para a embalagem de polietileno trançado.

Com relação ao armazenamento das sementes irradiadas ou não com ${ }^{60} \mathrm{Co}$ e armazenadas nos dois tipos de embalagem, verifica-se que a embalagem de PET proporcionou os melhores resultados frente à embalagem de polietileno trançado.

Na Figura 3 se constatou para os três tempos de armazenamento, diferença na germinação das sementes de amendoim irradiadas com ${ }^{60} \mathrm{Co}$ em todos os períodos de armazenamento e que a diminuição da germinação aumentou com a elevação das doses de irradiação.

Os resultados evidenciam que, à exceção do tempo de 8 dias, a viabilidade das sementes de amendoim reduziu estatisticamente dentro de cada tempo e entre os tempos à

A.

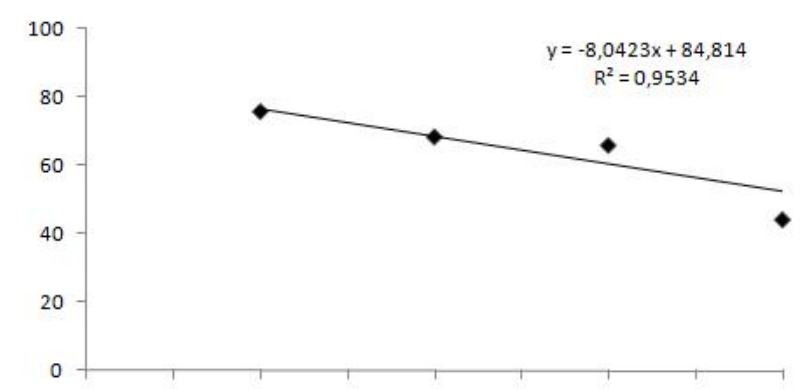

B.

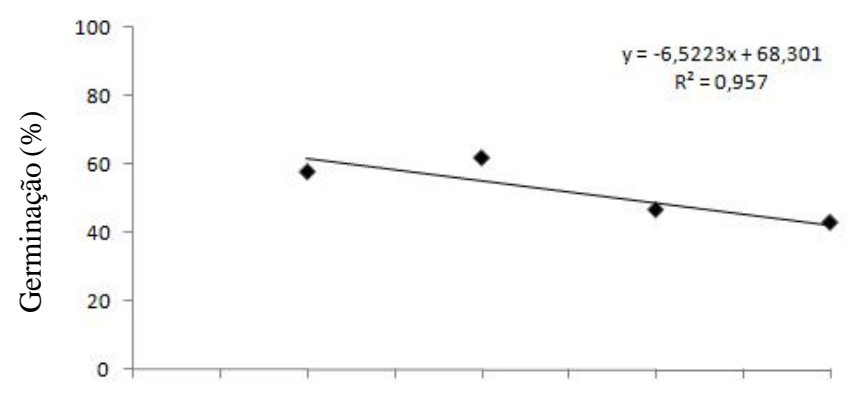

C.

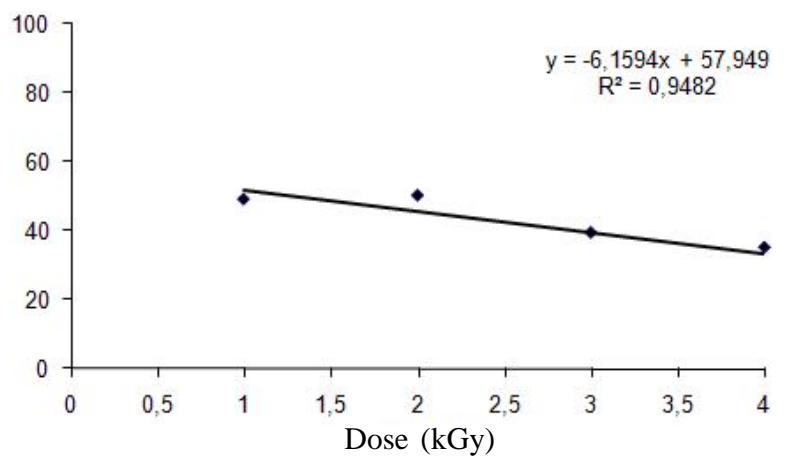

Figura 3. Porcentagem de germinação das sementes de amendoim irradiadas com ${ }^{60} \mathrm{Co}$ e armazenadas em ambiente não controlado por 8 (A), 30 (B) E 60 (C) dias 
medida em que se aumentaram as doses de irradiação e o tempo de armazenamento, comportamento que respalda os resultados encontrados por Ascheri et al. (2005) avaliando a qualidade fisiológica de sementes de soja irradiadas por raios $\mathrm{X}$ e armazenadas, em que as sementes de soja irradiadas tiveram sua qualidade fisiológica reduzida no decorrer do período de armazenamento, com perdas significativas em virtude do aumento da dosagem de raios $\mathrm{X}$.

\section{ConClusões}

1. Há redução da incidência da micoflora sempre que se eleva a dose da irradiação, com controle total (100\%) para a embalagem de PET na dose de 4,0 kGy e de 78,33\% para o armazenamento em embalagem de polietileno trançado.

2. Existe diferença de comportamento do fungo A. flavus nas sementes acondicionadas em embalagem de PET e polietileno trançado, tendo a de PET melhor controle.

3. O fungo Aspergillus niger foi eliminado a partir da dose $1,5 \mathrm{kGy}$ e o Penicillium a partir da dose de $2,5 \mathrm{kGy}$.

4. O tratamento com radiação gama afetou negativamente a germinação das sementes de amendoim.

5. A dose de $0,5 \mathrm{kGy}$ foi efetiva na germinação das sementes de amendoim e superior à da testemunha, no período de 30 e 60 dias.

6. Doses acima de 3,0 kGy comprometem totalmente a germinação das sementes.

\section{Agradecimento}

Ao Departamento de Energia Nuclear da Universidade Federal de Pernambuco, na pessoa da Professora Dra. Helen Khoury, e à CAPES, pelo apoio financeiro.

\section{LITERATURA CITADA}

Ascheri, D. P. R.; Oliveira Neto, M. C.; Devilla, I. A. Qualidade fisiológica de sementes de soja irradiadas por raios $\mathrm{x}$ e armazenadas. Revista Brasileira de Armazenamento, v.30, p.192-197, 2005.

Braghini R.; Pozzi, C. R.; Aquino S.; Rochl, O.; Corrêa B. Effects of y-radiation on the fungus Alternaria alternata in artificially inoculated cereal samples. Applied Radiation and Isotopes, v.67, p.1622-1628, 2009.

Brasil. Agência Nacional de Vigilância Sanitária. Resolução No 21 , de 21 de janeiro de 2001. Aprova o regulamento para a irradiação de alimento. Diário Oficial da República Federativa do Brasil, Brasília, 2001.

Brasil. Ministério da Agricultura e Reforma Agrária. Regras para Análise de sementes. Brasília: SNDA/DNDV/CLAV, 2009. 398p.

Diniz, E.; Silva, C. L.; Muniz, M. B.; Queiroga, V. de P.; Bruno, R. L. de A. Qualidade fisiológica e sanitária de sementes de amendoim (Arachis hypogaea L.) armazenadas. Revista Brasileira de Produtos Agroindustriais, v.3, p.61-72, 2001.
Fanaro, G. B.; Baldasso, J. G.; Crede, R. G.; Cláudio, T. B.; Sabundjian, I. T.; Guedes, R. L.; Villavicencio, A. L. C. H. Teste de germinação em sementes de girassol (Hellianthus annus L.) irradiadas. Revista de Sanidade Animal, Vegetal e Proteção Ambiental, v.71, p.178-180, 2004.

Hermanns, G.; Pinto, F. T.; Kitazawa, S. E.; Noll, I. B. Fungos e fumonisinas no período pré-colheita do milho. Ciência e Tecnologia de Alimentos, v.26, p.7-10, 2006.

Lima, K. S. C.; Lima, A. L. S.; Luchese, R. H.; Godoy, R. L. O.; Sabaa-Srur, A. U. O. Cenouras minimamente processadas em embalagens com atmosferas modificadas e tratadas com radiação gama: avaliação microbiológica, físico-química e química. Ciência e Tecnologia de Alimentos, v.23, p.240250, 2003.

Lukey, T. D. Hormesis with ionizing radiation. Boca Raton: CRC Press, 1980. 222p.

Neergaard, P. Seed pathology. London: Mac Millan, v.2, 1979. 839p.

Prado, G.; Carvalho, E. P.; Madeira, J. E. G. C.; Morais, V. A. D.; Oliveira, R. F. C.; Cardoso, V. N. Efeito da irradiação Gama $\left({ }^{60} \mathrm{Co}\right)$ na frequência fúngica de amendoim in natura em função do tempo de prateleira. Ciência e Agrotecnologia, v.30, p.930-936, 2006.

Prado, G.; Carvalho, P. E.; Oliveira, M. S.; Madeira, J. G. C.; Morais, V. D.; Correa, R. F.; Cardoso, V. N.; Soares, T. V.; Silva, J. F. M.; Gonçalves, R. C. P. Effect of gamma irradiation on the inactivation of aflatoxin $\mathrm{B} 1$ and fungal flora in peanut. Brazilian Journal of Microbiology, v.34, p.138-140, 2003.

Rossetto, C. A. V.; Viegas, E. C.; Lima, T. M. Contaminação fúngica do amendoim em função das doses de calcário e épocas de amostragem. Revista Bragantia, v.62, p 437-445, 2003.

Santos, T. S.; Almeida, F. de A. C.; Suassuna, T. de M. F.; Coutinho, W. M. Almeida, P. B. A. Resposta de sementes de amendoim a diferentes doses de radiação gama $\left({ }^{60} \mathrm{Co}\right)$. Revista Brasileira de Engenharia Agrícola e Ambiental, v.14, p.1074-1078, 2010.

Silva, F. de A. S. e; Azevedo, C. A. V. de. A new version of the assistat-statistical assistance software. In: World Congress on Computers in Agriculture, 4, 2006, Orlando. Anais... Orlando: American Society of Agricultural Engineers, 2006. p.393-396.

Tanaka, M. A. S.; Maeda, J. A.; Plazas, I. H. A. Z. Microflora fúngica de sementes de milho em ambiente de armazenamento. Scientia Agricola, v.58, p.501-508, 2001.

Toledo, T. C. F.; Canniatti-Brazaca, S. G.; Arthur, V.; Piedade, S. M. S. Composição, digestibilidade protéica e desaminação em cultivares brasileiras de soja submetidas à radiação gama. Ciência e Tecnologia de Alimentos, v.27, p.812-815, 2007.

Zanão, C. F. P.; Canniatti-Brazaca S. G.; Sarmento, S. B. S.; Arthur, V. Efeito da irradiação gama nas características físico-químicas e sensoriais do arroz (Oryza sativa L.) e no desenvolvimento de Sitophilus oryzae L. Ciência e Tecnologia de Alimentos, v.29, p.46-55, 2009. 